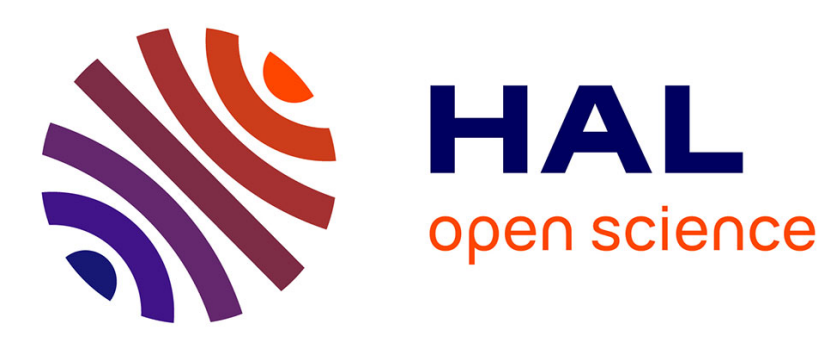

\title{
Nucleic acid enzymes based on functionalized nucleosides
} Marcel Hollenstein

\section{To cite this version:}

Marcel Hollenstein. Nucleic acid enzymes based on functionalized nucleosides. Current Opinion in Chemical Biology, 2019, 52, pp.93-101. 10.1016/j.cbpa.2019.06.007 . pasteur-02185135

\section{HAL Id: pasteur-02185135 \\ https://hal-pasteur.archives-ouvertes.fr/pasteur-02185135}

Submitted on 21 Dec 2021

HAL is a multi-disciplinary open access archive for the deposit and dissemination of scientific research documents, whether they are published or not. The documents may come from teaching and research institutions in France or abroad, or from public or private research centers.
L'archive ouverte pluridisciplinaire $\mathbf{H A L}$, est destinée au dépôt et à la diffusion de documents scientifiques de niveau recherche, publiés ou non, émanant des établissements d'enseignement et de recherche français ou étrangers, des laboratoires publics ou privés.

\section{(ㄷ)(1) $\$$}

Distributed under a Creative Commons Attribution - NonCommerciall 4.0 International 


\title{
HEAT TRANSFER IN SALT CAVERNS
}

\author{
Pierre Bérest \\ LMS, Ecole Polytechnique, CNRS UMR 7649, 91128 Palaiseau, France \\ berest@Ims.polytechnique.fr
}

\begin{abstract}
Several aspects of the thermodynamic behavior of salt caverns containing brine, oil, natural gas, air or hydrogen are discussed. It is shown that natural convection always appears in a liquid-filled cavern. This is not true in the case of gas caverns. Gas type, brine temperature at the cavern bottom and water vapor content are influential. Equations are obtained for the thermodynamic behavior of the fluids stored in a cavern during injection-withdrawal. Thermal evolution of a liquid-filled cavern at rest is slow; rapid injection and withdrawal are adiabatic and lead to small temperature changes. Heat capacity is much smaller in a gas cavern, temperature evolutions are much faster, and heat transfer from the rock mass must be taken into account. Evolutions can be described through a relatively simple equation. A simple model describing pressure and temperature in the wellbore during gas withdrawal is obtained.
\end{abstract}

Key words: Salt caverns; Gas storage caverns; CAES; Thermodynamics of salt caverns; Water vapor in a salt cavern

\section{Highlights}

- Conditions leading to natural convection in a cavern

- Inversion of temperature gradient in a gas cavern

- Equations for evolution of stored fluid temperature during injection-withdrawal

- Adiabatic and non-adiabatic behavior of a liquid-storage cavern 
- Thermodynamic behavior of a gas-storage cavern

- A closed-form solution for gas flow in a wellbore

\section{Introduction}

Salt caverns are deep cavities that are created by solution mining in both bedded and domal salt formations. They are connected to the ground level through a cased and cemented well. Strings are set in the well to allow injection or withdrawal of fluids into or from the cavern. These caverns range in volume from $V_{c}=5000 \mathrm{~m}^{3}$ to $5,000,000 \mathrm{~m}^{3}$ and in depth from $H=200 \mathrm{~m}$ to $H=2000 \mathrm{~m}$. When solution mining is completed, the cavern can be filled with crude oil, LPG, natural gas, hydrogen, compressed air, etc. During operation, fluids are injected or withdrawn from the cavern, and heat is exchanged with the rock mass, leading to pressure and temperature changes in the cavern. An abundant literature - mentioned in the course of the paper - was dedicated to various aspects of these thermodynamic effects in specific sites. The objective of this paper is to describe some of these effects and to prove that their main features can be captured by relatively simple models.

\section{Natural convection in a salt cavern}

In this section, the theoretical conditions leading to the onset of natural convection in a cavern are discussed.

\subsection{Fluid pressure in a cavern}

In a gas-storage cavern, gas pressure $(P)$ at casing-shoe depth $(H)$ varies between a maximum and a minimum pressure, typically $P_{\min }=\gamma_{\min } H, \quad P_{\max }=\gamma_{\max } H$, where $\gamma_{\text {min }}=0.6 \times 10^{-2} \mathrm{MPa} / \mathrm{m}$, and $\gamma_{\text {max }}=1.8 \times 10^{-2} \mathrm{MPa} / \mathrm{m}$ are the minimum and maximum "gradients". Maximum gas pressure is smaller than geostatic pressure, $P_{\infty}=\gamma_{R} H$, $\gamma_{R}=2.2 \times 10^{-2} \mathrm{MPa} / \mathrm{m}$. where $\gamma_{R}$ is the average volumetric weight of the rock formation. In natural gas caverns, gas used to be injected in summer and withdrawn in winter; at a $H=$ 1300-m depth, for instance, pressure varied from $8 \mathrm{MPa}$ to $22 \mathrm{MPa}$, typically. Prompted by the needs of energy traders, cycles tend to be more frequent. In compressed air storage, 
pressure is cycled every day between $5 \mathrm{MPa}$ and $7 \mathrm{MPa}$, typically. A gas-storage cavern contains gas and brine (hence, water vapor) as, during the initial gas fill (debrining) some brine, trapped into the sump at the cavern bottom, cannot be removed from the cavern. This brine, which is cold (see Section 4.2), plays a significant role in cavern thermodynamics. In liquefied or liquid (or supercritical) products storage, a central tube is left in the wellbore, and brine is injected in the central tube when hydrocarbon is withdrawn from the annulus between the cemented casing and the central tube (and vice versa): most often, cavern pressure is halmostatic, or $P_{h}=\gamma_{b} H, \gamma_{b}=1.2 \times 10^{-2} \mathrm{MPa} / \mathrm{m}$ is brine volumetric weight. However, cavern pressure is higher than halmostatic during tightness tests and lower during workovers. In the following, cavern pressure $\left(P_{c}\right)$ is the fluid pressure computed at casingshoe depth.

\subsection{Temperature in a cavern}

\subsubsection{Brine-filled cavern}

Figure 1 displays the temperature profile along a vertical axis in the cavern and access well of a brine cavern at Etrez, France, operated by Storengy ( ${ }^{1}$ Brouard, 1998). For this cavern, $V_{c}$ $=8000 \mathrm{~m}^{3}$, and the cavern's top and bottom depths are $920 \mathrm{~m}$ and $960 \mathrm{~m}$, respectively. On the left hand-side, a slope discontinuity can be observed at a 700-m depth. Its origin is in the contrast between the thermal conductivities of salt and marls. Heat flux through conduction is continuous through any discontinuity, $q=K_{R} d T_{R} / d z=K_{\operatorname{marl}} d T_{\operatorname{marl}} / d z$. For rock salt, $K_{R}=6 \mathrm{~W} / \mathrm{m} /{ }^{\circ} \mathrm{C}$; for marls, $K_{\operatorname{marl}}=3 \mathrm{~W} / \mathrm{m} /{ }^{\circ} \mathrm{C}$. The thermal gradient $d T / d z$ is divided by 2 at the interface between salt and marls. Another slope discontinuity, originating in convection, can be observed at shallow depth (a few dozen meters below ground level). The test is performed in February. At night, the wellhead is cold. Cold brine flows down in the wellbore to be replaced by warmer brine from below which, in turn, cools when in contact with the wellhead. The natural geothermal gradient is $G_{R}^{\infty}=d T_{R}^{\infty} / d z=1.6 \times 10^{-2 \circ} \mathrm{C} / \mathrm{m}$ in the salt formation. The thermal conductivity of the brine is $K_{b}=0.6 \mathrm{~W} / \mathrm{m} /{ }^{\circ} \mathrm{C}$ : if heat transfer in the cavern brine were through conduction, one would expect that the temperature gradient be larger in the brine mass than in the rock mass. In fact, the temperature gradient in the cavern is as small as $G_{c}=3.4 \times 10^{-3}{ }^{\circ} \mathrm{C} / \mathrm{m}$, clear evidence of the effects of natural convection. At the cavern bottom, the brine is warmer (hence, lighter) than it is at the cavern top. Due to 
buoyancy effects, brine rises; it cools along its upward path to the cavern top and ultimately returns to the cavern bottom, leading to the creation of convection cells. Brine is stirred by convection, and its temperature homogenizes. Numerical computations ( ${ }^{2}$ Karimi-Jafari 2007) using Boussinesq' linearization of the equations describing natural convection in the cavern were performed. Axisymmetry is assumed. The ADINA CFD modulus was used ( $k-\varepsilon$ model, no slip at cavern walls, velocity profile at cavern wall according to the Reichard law). On Figure 2, steady state flow is reached (after $1.110^{8} \mathrm{~s}$, or 12 days). Iso-values of the stream function $\psi=\psi(r, \theta), \quad v_{r}=-\partial \psi / \partial \theta, \quad v_{\theta}=\partial \psi / \partial r$ are represented on Figure 2, left: three convection cells develop, the lower cell rolls counter-clockwise. On Figure 2, right, velocity magnitude is represented; it is largest along the axis of symmetry where it is faster than 0.2 $\mathrm{mm} / \mathrm{s}(17 \mathrm{~m} /$ day).

Figure 3 displays the case of a brine-filled cavern at Stassfurt, Germany. The cavern volume is $V_{c}=13000 \mathrm{~m}^{3}$, and the cavern's top and bottom are $440 \mathrm{~m}$ and $650 \mathrm{~m}$, respectively. As in the previous example, the thermal gradient in the cavern is much smaller than the natural geothermal gradient, which is $G_{R}^{\infty}=1.8 \times 10^{-2 \circ} \mathrm{C} / \mathrm{m}$ in the salt formation - clear evidence of the onset of convection.

\subsubsection{Gas-filled cavern}

In a gas cavern, convection also can be observed. In fact, onset of convection is certain in a brine cavern (see Section 1.3). This is less true in a gas cavern and, in many cases, only the upper part of the cavern is the seat of perennial natural convection, as explained below.

Figure 4 represents the temperature profile in the S107 natural gas cavern at Stassfurt, Germany. ${ }^{4}$ Klafki et al. (2003) mention that the top and bottom of the cavern are $968 \mathrm{~m}$ and 1070 m, respectively. However, Fig. 4 suggests that actual depths might be slightly larger. Cavern volume is $V_{c}=288000 \mathrm{~m}^{3}$; it can be divided in three parts, whose radii are, from top to bottom, $20 \mathrm{~m}, 60-65 \mathrm{~m}$ and $46 \mathrm{~m}$. The cavern had been kept at rest for 2.5 months before the temperature log was run. Thermal convection is active in the upper part of the cavern: the thermal gradient there is much smaller than the geothermal gradient in the rock mass $\left(G_{R}^{\infty}=1.35 \times 10^{-2 \circ} \mathrm{C} / \mathrm{m}\right)$. In the lower part of the cavern, the gradient sign changes (gradient inversion) slightly above the cavern bottom. The lower part of the logging tool was below the 
brine-gas interface when the temperature at the lowest point on Fig. 4 was measured, which means that this point is representative of the temperature at the interface depth. Gradient inversion will be discussed in Section 4.

\subsection{First condition for onset of natural convection}

Gas thermal constants are given in Table 1 (at $\theta=25^{\circ} \mathrm{C}$ and $P_{N}=0.10325 \mathrm{MPa}$ ). Heat capacity, $C_{P}$, is an increasing function of pressure. At $20 \mathrm{MPa}$ and $30{ }^{\circ} \mathrm{C}$, it is $3400 \mathrm{~J} / \mathrm{kg} /{ }^{\circ} \mathrm{C}$ for $\mathrm{CH} 4$ and $1600 \mathrm{~J} / \mathrm{kg} /{ }^{\circ} \mathrm{C}$ for air ( ${ }^{6}$ Schlichtenmayer et al. 2015). In this paper, we are mainly interested in a semi-quantitative description of the phenomena observed in actual caverns rather than in accurate numerical computations. For this reason, dependency of the thermal parameters upon temperature is not taken into account. Note, however, that it can play a role. For instance, it is known that, for a given geometry, rotation of convection cells is in opposite directions when a gas and a liquid is considered, as the sign of $d \mu / d T$ ( $\mu$ is the fluid viscosity) is not the same.

Mechanical equilibrium in a fluid requires that temperature be a function of depth only. At equilibrium, $\operatorname{gra} d P=\rho(P, T) \vec{g}$; hence, $\operatorname{cu} \vec{u} r l(\rho \vec{g})=\left(\frac{\partial \rho}{\partial T}\right) \vec{g} \wedge \operatorname{gr} \vec{a} d T=\overrightarrow{0}$ and $T=T(z)$. Such an equilibrium is stable when the temperature gradient is oriented upward $(G=d T / d z<0)$. A downward-oriented temperature gradient $(G=d T / d z>0) 0)$ is not a sufficient condition for onset of natural convection (i.e., instability). Even in an infinite fluid medium (No viscous boundary layer at cavern wall or viscous dissipation in the fluid body is considered.), this gradient must be larger than a certain threshold, the adiabatic gradient, which can be defined as follows. When a fluid particle rises by $d z<0$, its pressure immediately decreases by $d P=\rho g d z$ to reach mechanical equilibrium with the surrounding fluid. Because of this expansion, liquid temperature drops. As a consequence, heat transfer from the surrounding fluid takes place to reach thermal equilibrium. However, this process is much slower than the mechanical process; in fact, when particle rise is fast, insufficient time is given for heat transfer, and particle expansion is adiabatic. In the case of a non-viscous ideal gas, an adiabatic expansion can be described as $T d s=C_{P} d T_{a d}-d P / \rho=0$, where $s$ is the gas entropy per unit of mass, $C_{P}$ is the gas thermal capacity (when gas pressure is kept 
constant), $\rho=P / r T$ is its density, from which $d T_{a d}=g d z / C_{P}$. This temperature change must be compared to the geothermal temperature change, or $d T_{c}=G_{R}^{\infty} d z$. When $G_{a d}=g / C_{P}<G_{R}^{\infty}$, the rising particle is warmer (and lighter) than its environment and keeps rising: convection appears. Gravity acceleration is $g=10 \mathrm{~m} / \mathrm{s}^{2}$; heat capacity is $C_{P}=3400 \mathrm{~J} / \mathrm{kg} /{ }^{\circ} \mathrm{C}$ for natural gas (at $30^{\circ} \mathrm{C}$ and $20 \mathrm{MPa}$ ), $C_{P}=1100 \mathrm{~J} / \mathrm{kg} /{ }^{\circ} \mathrm{C}$ for air (at $30^{\circ} \mathrm{C}$ and $7 \mathrm{MPa}$ ), and $C_{P}=14000 \mathrm{~J} / \mathrm{kg} /{ }^{\circ} \mathrm{C}$ for hydrogen. In other words, as $G_{R}^{\infty}=1.6-1.8 \times 10^{-2}{ }^{\circ} \mathrm{C} / \mathrm{m}$ in a salt formation, onset of convection is likely in an air-storage facility $\left(g / C_{P}=9 \times 10^{-3}{ }^{\circ} \mathrm{C} / \mathrm{m}\right)$, highly likely in a natural gas storage $\left(\mathrm{g} / C_{P}=3 \times 10^{-3}{ }^{\circ} \mathrm{C} / \mathrm{m}\right)$ and certain in a hydrogen storage $\left.\left(g / C_{P}=0.7 \times 10^{-3}{ }^{\circ} \mathrm{C} / \mathrm{m}\right)\right)$. In the case of a liquid, $d T_{a d}=\alpha T d P / \rho C_{P} ; \alpha=-\partial \rho(T, P) / \partial T$ is the thermal expansion coefficient (for a gas, $\alpha T=1$.) For brine, $\alpha_{b}=4.4 \times 10^{-4} /{ }^{\circ} \mathrm{C} ; \quad T=300 \mathrm{~K}$ is typical, $C_{P}^{b}=3800 \mathrm{~J} / \mathrm{kg} /{ }^{\circ} \mathrm{C}$, and $G_{a d}=3.5 \times 10^{-4}{ }^{\circ} \mathrm{C} / \mathrm{m}$ is much smaller than the geothermal gradient: onset of convection is certain in a brine-filled cavern, as suggested by the examples shown on Figs. 1 and 3. However, these simple arguments fail to take into account several factors, which will be discussed below.

\subsection{Induced geothermal gradient}

In the previous section, it was assumed that the geothermal gradient is the same in the cavern $\left(G_{c}^{\infty}\right)$ as in the rock mass $\left(G_{R}^{\infty}\right)$. In fact, because gas (or liquid) conductivity is less than rock conductivity, the geothermal gradient at rest (when no convection takes place) is larger in the cavern fluid than in the rock mass. The adiabatic gradient $\left(G_{a d}\right)$ must be compared to $G_{c}^{\infty}$ rather than $G_{R}^{\infty}$. Let $T_{R}$ and $T_{F}$ be the temperature distributions at rest in the rock mass and in the cavern fluid, respectively. Both are harmonic functions, $\Delta T_{R}=0$ and $\Delta T_{F}=0$. Consider, for instance, the case of a spherical cavern, radius $a$, whose origin is at the center of the cavern whose depth is $H$; spherical coordinates are used, and $z=H+r \cos \theta$ is oriented downward. Rock temperature and fluid temperature are $T_{R}(r, \theta)=T_{\infty}(H)+G_{R}^{\infty} r \cos \theta+A a^{3} \cos \theta / r^{2}$ and $T_{F}=T_{\infty}(H)+G_{c}^{\infty} r \cos \theta$, respectively; $A$ and $G_{c}^{\infty}$ are two constants. At the cavern wall, temperatures and heat flux are continuous, $T_{R}=T_{F}$ and $K_{F} \partial T_{F} / \partial n=K_{R} \partial T_{R} / \partial n$, from which it is inferred that the geothermal gradient at rest in the cavern is $G_{c}^{\infty} / G_{R}^{\infty}=3 K_{R} /\left(2 K_{R}+K_{F}\right)$. In most cases, $K_{F}$ is much smaller than $K_{R}$ (for rock 
salt, $K_{R}=6 \mathrm{~W} / \mathrm{m} /{ }^{\circ} \mathrm{C}$; for brine, $K_{F}=0.6 \mathrm{~W} / \mathrm{m} /{ }^{\circ} \mathrm{C}$; for air or for hydrogen, $K_{F}=0.026 \mathrm{~W} / \mathrm{m} /{ }^{\circ} \mathrm{C}$ or $0.185 \mathrm{~W} / \mathrm{m} /{ }^{\circ} \mathrm{C}$ respectively - see Table 1 ) and the "induced" geothermal gradient in the fluid at rest is larger than the geothermal gradient in the rock mass (for air, $G_{c}^{\infty}=1.5 G_{R}^{\infty}$ ), making onset of convection somewhat easier than predicted in Section 1.3.The induced geothermal gradient also depends on cavern age. During the leaching period, which is several years long, cold water pumped from a lake or a shallow aquifer is injected in the cavern. When leaching is completed, the cavern brine is colder than the rock mass by a couple of dozen of ${ }^{\circ} \mathrm{C}$. After debrining, the cavern walls are cold ( ${ }^{7}$ Walden et al., 2001), and the same can be said of the brine left at the cavern bottom. Warming brine and rock mass is slow ( ${ }^{8}$ Fosse and Røvang, 1998), as discussed later. The transient induced geothermal gradient is difficult to compute.

\subsection{Wet gas and dry gas}

In many cases (Section 2), cavern gas is saturated with water vapor. (Equilibrium with sump brine must be reached.) In principle, when computing adiabatic gas expansion, the effect of condensation must be taken into account, and the wet adiabatic gradient is smaller than the dry adiabatic gradient ('Sivoukhine, 1982, p. 499-501). Let $m_{g}, m_{v}, m_{L}$ be the mass of gas, water vapor and liquid water, respectively. When condensation starts, $m_{L}=0$ and $\dot{m}_{L}+\dot{m}_{v}=0$. The vapor pressure at saturation, $P_{v}^{s}(T)$, is a function of temperature only.

During adiabatic evolution, the entropy of the mixture, $s=\sum_{i} m_{i} s_{i}, i=v, L, g$, is constant, and

$$
\left(s_{v}-s_{L}\right) d m_{v}+\frac{m_{v}}{T}\left(C_{P}^{v} d T_{a d}-\frac{d P_{v}^{s}}{\rho_{v}}\right)+\frac{m_{v}}{T}\left(C_{P}^{g} d T_{a d}-\frac{d P_{g}}{\rho_{g}}\right)=0
$$

Let $L=\left(s_{v}-s_{L}\right) T$ be the latent heat capacity for the liquid-vapor transition; taking into account $d P_{v}^{s} / d T=L \rho_{v} / T$ (Clapeyron's law), $d P_{g}=\rho_{g} g d z$ (mechanical equilibrium), and $P_{i}=\rho_{i} r_{i} T$ for $i=v, g$ (state equations) 


$$
\left.\frac{d T}{d z}\right|_{\text {wet }}=\frac{g}{C_{P}^{g}\left(1+\frac{r_{g} P_{v}^{s}}{r_{v} P_{g}}\left[L\left(\frac{L}{r_{V} T^{2}}-\frac{2}{T}\right)+C_{P}^{v}\right] / C_{P}^{g}\right)}
$$

The difference between the wet adiabatic gradient $G_{a d}^{w e t}$ and the dry adiabatic gradient $G_{a d}^{d r y}$ (which equals $g / C_{P}^{v}$ ) is proportional to the $P_{v}^{s} / P_{g}$ ratio. This ratio between vapor pressure and gas pressure is not very small in the atmosphere $\left(P_{g}=P_{a i r}=0.1 \mathrm{MPa}\right.$; at $\theta=30^{\circ} \mathrm{C}, P_{v}^{s}\left(30^{\circ} \mathrm{C}\right)=4.25 \mathrm{kPa}$ and $P_{v}^{s} / P_{a i r}=4 \%$, see Section 2$)$ and the difference is significant when meteorological phenomena are concerned. The same is not true for a gas cavern, in which $P_{g}=10 \mathrm{MPa}$, and, when $\theta=50^{\circ} \mathrm{C}, P_{v}^{s}\left(50^{\circ} \mathrm{C}\right)=9 \mathrm{kPa}$ are typical.

\subsection{Second condition for onset of natural convection}

The condition for onset of natural convection, $G_{a d}<G_{c}^{\infty}$, is a necessary condition. In the analysis, viscous effects were not taken into account. In fact, in a cavity of (very) small dimensions, viscosity can impede natural convection. The set of equations describing natural convection in a cavern (conservations of mass, energy and momentum) must be solved numerically. However, steady-state convective flow can be described through linearized equations (Boussinesq approximation) ( ${ }^{10}$ Landau and Lifschitz, 1971). This set of equations highlights the significance of three dimensionless constants, Prandtl, Grashof and Nusselt numbers: $\operatorname{Pr}=v / k$, where $v=$ kinematic viscosity, $k=$ gas thermal diffusivity; $G r=g \alpha G a^{4} / v^{2}$, where $a=$ cavern characteristic length, $\alpha=$ the thermal expansion coefficient of the fluid, and $G=G_{c}-G_{a d}$, where $G_{c}$ is the actual thermal gradient in the cavern; and $\mathrm{Nu}=\bar{H} a / K_{F}$ where $\bar{H}$ is the heat-transfer coefficient at the cavern wall (defined in Section 5.1). Natural convection starts when $G$ is larger than the value given by a certain combination of $\mathrm{Gr}, \mathrm{Pr}$ and $\mathrm{Nu}$ that depends on cavern shape and boundary conditions. For an elongated cylindrical cavern, convection appears when the Rayleigh number $\mathrm{Ra}=\mathrm{Pr} \cdot \mathrm{Gr}$ is larger than a value that depends on $\mathrm{Nu}$ and is smaller than $10^{3}\left({ }^{10}\right.$ Landau and Lifschitz, 1971). The Prandtl number can be written $\operatorname{Pr}=\mu C_{P} / K$; for most gases (Table 1), dynamic viscosity is in the range $\mu=1-2 \times 10^{-5}$ Pa.s $\quad C_{P}=1-2 \times 10^{3} \mathrm{~J} / \mathrm{kg} / \mathrm{K}, \quad$ and $\quad K=2 \times 10^{-5}$ Pa.s. Also, $g=10 \mathrm{~m} / \mathrm{s}^{2}, G=1.5 \times 10^{-2}{ }^{\circ} \mathrm{C} / \mathrm{m}, \alpha_{g}=3 \times 10^{-3} /{ }^{\circ} \mathrm{C}$ and, for standard caverns, $a=10-50 \mathrm{~m}$. 
The Rayleigh number $(=\operatorname{Pr} . G r)$ is larger than $10^{10}$, a figure for which natural convection is turbulent. In other words, a cavern contains so large a fluid body that the condition relative to the adiabatic gradient is a sufficient condition for onset of convection. For instance, ${ }^{4} \mathrm{Klafki}$ et al., 2003 computed natural convection in the cavern represented on Fig. 4. A stable vortex (The horizontal component of gas speed was high.) was observed in the lower part of the cavern, an independent convection cell (upstream at the wall, downstream in the center) was observed in the main cavern, and flow was unsteady in the narrow upper part. Maximal velocities were smaller than $0.5 \mathrm{~m} / \mathrm{s}$. This computation highlights the importance of cavern shape on the pattern of convection cells pattern (see also Fig. 2).

\section{Water vapor in the cavern}

Moisture content is a critical issue when operating a gas cavern. It was proven in Section 1.5 that its influence on the onset of natural convection is minor. However, when gas containing water vapor is withdrawn from a cavern, gas pressure and temperature drop in the wellbore, leading to the possible formation of hydrates in the upper part of the wellbore (a severe operational problem, discussed in Section 6). In fact, natural gas injected in a cavern is relatively dry. In France, for instance, water vapor concentration (or $c_{v}=m / V_{N}=P_{v} P_{N} / r_{v} T_{N} P_{g}$, where the subscript $N$ is for normal conditions, $P_{N}=0.10325 \mathrm{MPa}$, and $T_{N}=273$ K.) must be less than $c_{v}=46 \mathrm{mg} / \mathrm{Nm}^{3}$ (11 Louvet et al., 2018). However, there is a thin brine layer at the cavern wall $\left(70 \mathrm{~cm}^{3} / \mathrm{m}^{2}\right.$, see ${ }^{12}$ Kökritz and Walden, 1994) and a (much larger) amount of brine in the sump at the cavern bottom mentioned in Section 1.1. Equilibrium requires, at least in principle, that brine is saturated with dissolved natural gas and that cavern gas is saturated with water vapor. The partial pressure of water vapor at saturation, or $P_{v}{ }^{s}$, is a function of temperature (for instance, Rankine's formula predicts: $P_{v}^{s}[T]=f P_{a t m} \exp (13.7-5120 / T)$, with $T$ in $\mathrm{K}$; for pure water, $f=1$, and for saturated brine, $f=$ 0.75 , according to Raoult's law).

Following gas injection or withdrawal, temperature changes in the cavern, and gas is either over- or under-saturated with water vapor in the new temperature conditions. Water vaporizes or condenses until, after some time, equilibrium is reached again. Consider an airstorage cavern of volume $V_{c}=400000 \mathrm{~m}^{3}$ : air is withdrawn rapidly from the cavern, whose 


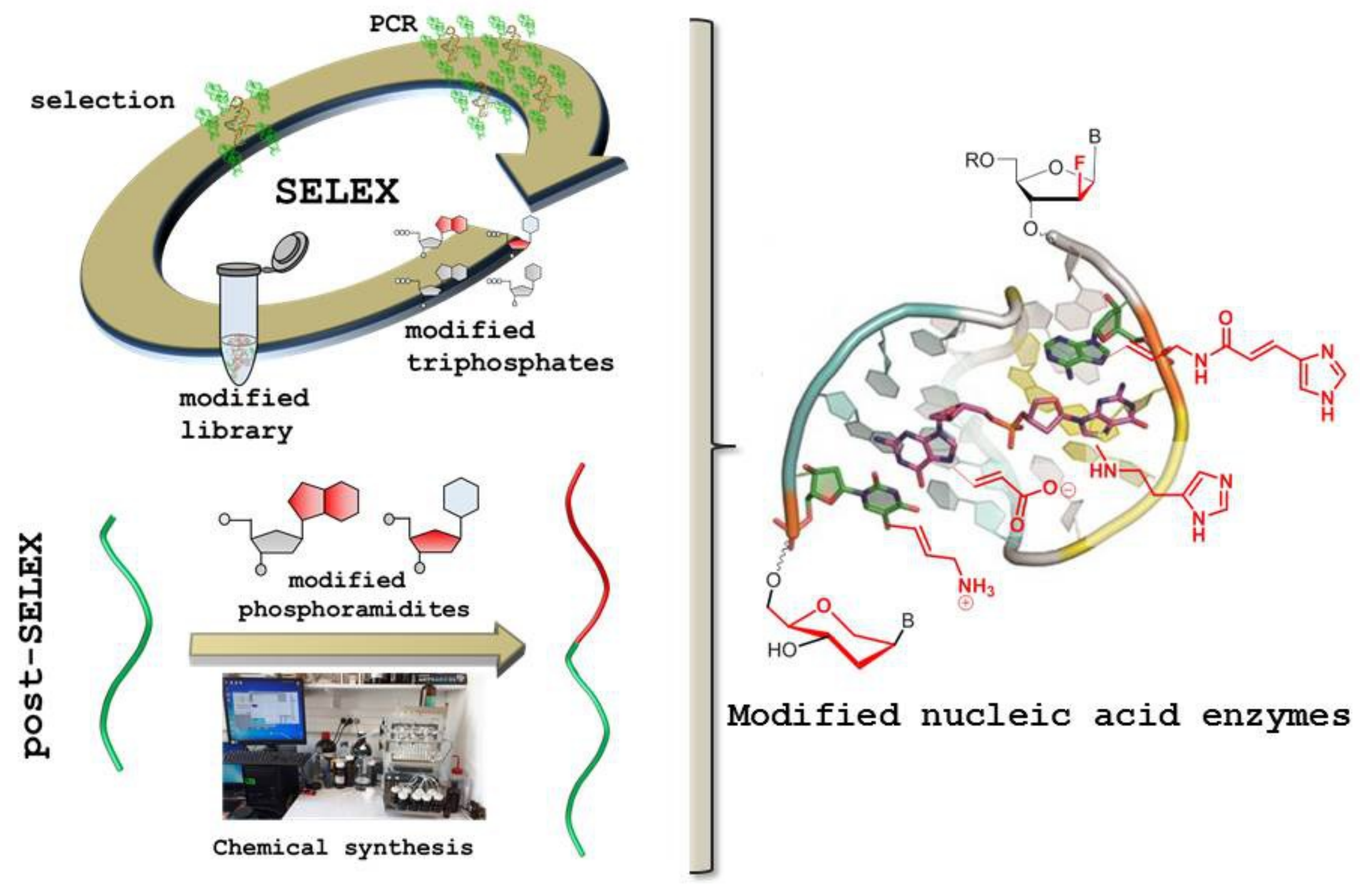

